\title{
Twittering to increase student engagement in the university classroom
}

\author{
Bridget K. Welch* \\ Department of Sociology \& Anthropology \\ Western Illinois University, USA \\ E-mail: bk-welch@wiu.edu
}

\section{Jess Bonnan-White}

School of Social and Behavioral Sciences

The Richard Stockton College of New Jersey, USA

E-mail: Jessica.White@ stockton.edu

*Corresponding author. Authorship order was determined by a coin flip.

\begin{abstract}
In this paper, we explored the research question: Does Twitter in a large-lecture format university course produced a difference in levels of selfreported student engagement? To do so, we utilize a quasi-experimental design testing the effect of Twitter on student engagement in introductory sociology and anthropology courses. Our hypotheses predicted that students using Twitter would report higher levels of five forms of student engagement (academic, intellectual, peer, and beyond-class engagement, along with an overall engagement variable). While peer-reviewed literature and others' anecdotal reporting would lead us to expect a positive result, we found no significant difference in any form of engagement when Twitter was part of the course than when it was not. In fact, we found that students enrolled in the control (nonTwitter) condition perceived significantly higher levels of academic engagement then those in the experimental (used Twitter) condition. We also included a second set of hypothesis predicting that students who reported enjoying using Twitter would perceive of themselves as more engaged than those who did not enjoy Twitter. These hypotheses were supported across all forms of engagement. We report these findings and utilize comments from an open-ended questionnaire to explore potential reasons accounting for these differences and how students perceived Twitter as a classroom tool.
\end{abstract}

Keywords: Student engagement; Twitter; Social media; Generation Net

Biographical notes: Bridget K. Welch is an Assistant Professor of sociology at Western Illinois University. Her areas of teaching and research include: social psychology; race, class, and gender; and research methods. Previous teaching research has examined the use of Mario Kart Nintendo ${ }^{\circledR}$ Wii to create intergroup conflict.

Jess Bonnan-White is a Visiting Assistant Professor of anthropology at The Richard Stockton College of New Jersey. Her areas of teaching and research include conflict resolution, international development, Middle Eastern culture, and primate evolution. Previous teaching research has examined the definition of evolution as presented in cultural anthropology textbooks and the role of power in classroom group activities. 


\section{Introduction}

Launched in 2006, Twitter is a relatively new social media tool. In 2010 and 2011, Twitter took on new prominence as popular media emphasized its role in social events such as the "Arab Spring" popular revolutions (Cottle, 2011). With its 140-character limit, Twitter provides users the ability to send questions, information, and opinions to a global audience eagerly watching their "feed" on computers, smartphones, and other digital devices. Whereas recent studies have suggested that over half of the world's Twitter users hail from North America (Exploring the use of Twitter around the world, 2010), Twitter's penetration is highest (as measured by proportion of international Internet users) in Indonesia, Brazil, and Venezuela (Singer, 2010). In fact, only 13\% of online American adults access Twitter (Smith, 2011, June 1). These reports conclude that the United States remains behind other countries in Twitter penetration. Yet, the question remains as to whether the current supposed tech-savvy generation (particularly those enrolled in college) would positively respond to the use of this technology in the classroom.

Literature suggests that increasing student engagement is positively correlated with student achievement, albeit in differing magnitudes among various student populations (Carini, Kuh, \& Klein, 2006; Kuh, Cruce, Shoup, Kinzie, \& Gonyea 2008). Research on methods encouraging student engagement in college classrooms frequently discusses the use of technology (Hannafin \& Land, 1997; Revere \& Kovach, 2011). In particular, this discussion has focused on the use of social media tools in the context of creating a stimulating online class environment (Dunlap \& Lowenthal, 2009). An argument often forwarded is that technology, particularly social media tools (e.g. Facebook, Twitter, micro-blogging), encourages student-student and student-faculty interaction. This interaction, in turn, provides a framework for increased student engagement. There is stress on meeting the current generation of tech-savvy students on familiar territory through social media technology to maintain student engagement and enhance learning (Baird \& Fisher, 2005; Hannay \& Fretwell, 2011, Hastie, Chen, \& Smith, 2011; Kassens-Noor, 2012; Laird \& Kuh, 2005; Luo \& Gao, 2012; Rutherford, 2010). The message is that by extending pedagogical approaches to include social media instructors can adapt to the learning styles, styles of social networking, and demands of the current college-aged generation (Galagan, 2010; Silus, Millumäki, Huhtamäki, Tebest, Meriläinen, \& Pohjolainen, 2010). This paper explores the underlying assumption of this message by addressing the following research question: Does using Twitter in a largelecture format university course produce a difference in levels of self-reported student engagement?

Although literature measuring the effect of Twitter on academic performance and engagement in the college classroom is increasing, it is largely based on anecdotal experience, case studies with small-sample sizes (e.g., Wakefield, Warren, \& Alsobrook, 2011; Kassens-Noor, 2012), or instructor-instructor dialogue at technology conferences, training sessions, or blogging sites. There are few large-scale studies with explicit hypotheses and repeatable measurements (Junco, Heibergert, \& Loken, 2011; Lowe \& Laffey, 2011; Fox \& Varadarajan, 2011). These case studies mainly take place in K-12 or "online" classrooms. While both are important areas to examine, here we offer an empirical test of the effect of Twitter on student engagement in a traditional undergraduate classroom environment (i.e. face-to-face, large lecture hall environment). Further, we include classes taught by two faculty members in an attempt to mitigate any 
effect of the instructor's personal teaching style on students' self-reported levels of engagement.

Thus, offering one of the first empirical examinations on Twitter in traditional face-to-face college undergraduate classrooms, we investigate its application in introductory courses and resulting effects on student engagement using a quasiexperimental methodology. Before discussing our research, we review the literature on student engagement in the college classroom. Second, we briefly discuss Generation Net, one of many appellations used to describe the current generation of traditional collegeaged students, and what they expect in terms of technology. Finally, we discuss the small body of academic literature that exists analyzing the use of Twitter in the college classroom.

\section{Student engagement}

Student engagement, as defined by Kuh (2009) and used by Krause and Coates (2008), is "the time and effort students devote to activities that are empirically linked to desired outcomes of college and what institutions do to induce students to participate in these activities" (Kuh, 2009, p. 683). The development of engagement as a pedagogical concern rests on the recognition that the amount of energy students invest on academic and campus-based tasks (e.g., studying, peer and teacher interaction, involvement in campus events and groups, meeting high academic expectations) is positively associated with an effective academic experience (Kuh et al., 2008; Kuh, 2009). Several authors have focused on the importance of effort made by faculty and institutions to provide conditions for enhanced learning opportunities (Krause \& Coates, 2008; Pascarella \& Terenzini, 2005)

There are many factors that affect student engagement. For example socioeconomic circumstances, racial and ethnic backgrounds, academic preparation, and generational experience (first-generation students versus students with universityeducated parents) all have implications for level of student engagement (Pascarella, Pierson, Wolniak, \& Terenzini, 2004; Pascarella \& Terenzini, 2005). The studies by Pascarella and colleagues indicated that engagement is impacted by faculty concerns toward students, involvement in campus and peer networks, access and knowledge of campus academic resources, and ability to develop new academic skill sets. As we discuss below, any attempt to universalize student experiences may result in a lack of recognition of how these factors continue to interact in the university classroom.

Despite these concerns, it is commonly accepted that engagement and academic achievement are tightly intertwined. An example of this thinking is reflected by the National Research Council (2003) in stating that in order for students to feel motivated to learn, they need to feel that they have, "competence and control, beliefs about the value of education, and a sense of belonging" (National Research Council, 2003, p. 4). In other words, they need to feel engaged. With the literature indicating that engagement is key to academic achievement and the retention of students, it should not be surprising that there has been incredible investment into research on how to maximize engagement in the classroom. Indeed, colleges and universities have integrated measures of it into assessment of institutional learning outcomes, resource allocation decisions, and curriculum strategies (e.g., Ewell, 2008; Gonyea \& Kuh, 2009).

In their analysis of student engagement, Krause and Coates (2008) identified seven categories of engagement: Transition, Academic, Peer, Student-Staff, Intellectual, 
Online, and Beyond- Class. Four of these engagement categories (Academic, Peer, Intellectual, and Beyond-Class) directly relate to the goals of the current study, as they addressed how students perceived their relationships with different actors comprising their university experience:

- The Academic Engagement Scale (AES) was designed to assess the level of agency a student feels to be able to manage one's time, organize study needs, and develop successful study strategies, as well as a student's self-awareness within an academic setting.

- The Peer Engagement Scale (PES) to gain a measure of collaborative activities that require interaction with other student peers.

- The Intellectual Engagement Scale (IES) explored students' perceptions of the stimulation and challenge offered by their subjects.

- The Beyond-Class Engagement (BES) measured perceptions of student involvement in extra-curricular activities and social connections outside of the classroom environment (Krause \& Coates, 2008).

Krause and Coates calculated two additional scales, Student-staff and Online Engagement Scales; as we were not measuring connection with academic staff (outside of the primary faculty member) or online practices of students (outside of Twitter use), we chose not to include these scales in our analysis.

\section{Generation Net}

Born in the 1980s, Generation Net (or "digital natives") is the first to mature online creating in them "distinctive ways of thinking, communicating, and learning" (Barnes, Marateo, \& Ferris, 2007; see also Oblinger \& Oblinger, 2005). The ability to instantly search and find information has been argued to make students demand a different type of classroom and multiple modes of communication with each other and the instructor (Tapscott, 1998; Oblinger \& Hagner, 2005). Further, the argument is that these 'digital natives' - raised in an environment characterized by digital equipment - have an innate knowledge and regular usage pattern of information and communication technology (Prensky, 2001a, 2001b). This social context is thought to increase students' ability to multitask, increase their preference for experiential learning environments, create a dependence on social communication tools, and make them capable of integrating technology into a team-oriented work ethic (Bennet, Maton, \& Kervin, 2008). The result is the notion that the "new" learning and cognitive features of this generation requires teaching styles to adjust to student demands or risk being ineffective (Galagan, 2010; Hannay \& Fretwell, 2011).

Yet, as Ramaley and Zia (2005) reported, "not everyone is a member of the Net Generation - not because of age but because of access to technology" (2005: 8.1). Recent research has started to challenge the "digital natives" characterization by arguing that social factors and context mediate technological knowledge (e.g., Combes, 2006, 2007, 2008; Nicholas, Rowlands, \& Huntington, 2008). The idea that social media needs to be utilized to maintain student engagement is successful only as far as students have experience with the technology (Ramaley \& Zia, 2005; Wakefield, Warren, \& Alsobrook, 2011; Hargittai \& Litt, 2012). Reports of cell phone and smart phone usage (frequently utilized modes of technology used to access social media sites), and reports on Twitter usage, cast serious doubt on the "digital native" characterization. For example, two 2011 
surveys (Purcell, 2011; Smith, 2011b) found that 35\% of adult Americans own a smartphone whereas only $8 \%$ report owning a tablet-computer (e.g., iPad, Samsung Galaxy). Surveys also clearly indicated that access and use of this technology varied by race, geographic locale, and socio-economic status as well (Azevedo, 2011; Livingston, 2011; Smith, 2012).

To the extent that teachers rely on social media in their attempts to engage students, they risk being misguided as long as universities recruit students from a variety of racial, ethnic, geographic, and economic backgrounds. With the "digital native" characterization in mind, we explore the association between Twitter use, academic achievement and student engagement for the students enrolled in four sections of two introductory level general education courses at a mid-sized comprehensive state university. This is an important examination because, as we discuss next, these social media tools are already entering the classroom (Blankenship, 2011).

\section{Social media as a pedagogical tool}

Social media tools are quickly being adapted into the college classroom. A survey of over 2,000 faculty found that 80 percent were using some form of social media in their classroom (Moran, Seaman, \& Tinti-Kane, 2011). Further, two-thirds of faculty utilized social media (mainly YouTube) during a class period while $30 \%$ posted material for students to consider outside of class. Yet, even though most faculty and many students utilize cites like Facebook and Twitter in their private lives, these sites (particularly Twitter) have been slower to gain a foothold in pedagogy.

In response to the increase of use, there is a growing body of literature addressing whether social media in the classroom enhances students' perception of social presence (the sense of being involved in the classroom) and how technology affects this process (Junco, Heibergert, \& Loken, 2011; Rutherford, 2010; Wakefield, Warren, \& Alsobrook, 2011). In particular, a number of authors as cited in Wakefield, Warren, and Alsobrook (2011) have noted a relationship between social presence, perceived learning, interaction in the classroom, and course satisfaction. Social media tools, therefore, are argued to provide the means to foster communication in classrooms (Tyma, 2011), which in turn supplements perceptions of engagement and perceptions of quality of education (Rutherford, 2010).

Junco, Heibergert, and Loken (2011) provided the first large-scale (119 students) investigation of Twitter in first-year university classrooms. These authors used Twitter in a variety of ways to supplement course material in experimental sections of a pre-health majors-only course. Using grade point average scores and portions of the National Survey of Student Engagement survey, the authors found that both reports of student engagement and GPA results were significantly higher in the experimental (Twitter) course sections. The authors noted that in addition to meeting course requirements, students participating in the study used Twitter to develop interpersonal relationships and to candidly discuss personal subjects.

The literature on Twitter usage in the university classroom that does exist is generally positive in nature (Tyma 2011). For example, classrooms at Purdue University have been noted to include Twitter during lecture as a method for students to ask questions and make comments. Young (2009) argued that the instructor found that Twitter "alters classroom power dynamics and signals to students that they're in control." Monica Rankin (2009), at the University of Texas at Dallas, has popularized her 
experiences with Twitter through a blog that features a student video on benefits of the technology (ibid). Rankin instituted non-electronic methods for feedback as well (e.g. pen and paper submissions) for those who did not want to use the technology - indicating that enjoyment of the social networking site may also impact student outcomes. These case studies raise questions about how enjoyment of Twitter use may affect student outcomes.

As previously stated, our research question addresses whether using one social media tool, Twitter, in large-lecture format university courses produces a difference in levels of self-reported student engagement. To do so, we examine the following hypotheses in two major categories:

\section{Engagement:}

a. Those who used Twitter in the classroom will perceive themselves as more engaged than those who did not use Twitter.

b. Those who used Twitter in the classroom will perceive themselves as more academically engaged than those who did not use Twitter.

c. Those who used Twitter in the classroom will perceive themselves as more engaged with their peers than those who did not use Twitter.

d. Those who used Twitter in the classroom will perceive themselves as more intellectually engaged than those who did not use Twitter.

e. Those who used Twitter in the classroom will perceive themselves as more engaged beyond the classroom than those who did not use Twitter.

\section{Enjoyment of Twitter and Engagement:}

a. Those who enjoyed Twitter in the classroom will perceive themselves as more engaged than those who did not.

b. Those who enjoyed Twitter in the classroom perceive themselves as more academically engaged than those who did not.

c. Those who enjoyed Twitter in the classroom will perceive themselves as more engaged with their peers than those who did not.

d. Those who enjoyed Twitter in the classroom will perceive themselves as more intellectually engaged than those who did not.

e. Those who enjoyed Twitter in the classroom will perceive themselves as more engaged beyond the classroom than those who did not use.

\section{Methods}

Below we outline the methodology for this study. First we discuss the participants. This is followed by a discussion of materials, including measures. Finally, we outline the procedure of the study.

\subsection{Participants}

Participants were undergraduates enrolled in two sections of "Introduction to Sociology" and two sections of "Introduction to Cultural Anthropology" offered in the fifteen-week Fall 2011 semester. Due to confidentiality agreements with the institutional review board, 
we do not have data on race, grade level, or sex of the students. However, traditional introductory level students are first-year students within Sociology courses and cover a variety of levels in the Anthropology courses. During the semester this study took place, the main campus of the university demonstrated racial diversity represented by White (73.2), Black (14.4), and Hispanic (6.0) students. Further, 52.3\% of the campus were males and with $47.7 \%$ female. As general education courses, our demographics tend to closely reflect those of the overall university. With cross-wise deletion for missing data, students opting out of taking the survey, and student withdrawals, the final total sample was 205. Accordingly, the numbers of students in each analysis varies and are reported separately in the tables below.

\subsection{Materials}

Data were collected via a paper / pencil instrument distributed during one class period in each course during the second to last week of the semester. This study consists of one main dependent variable: engagement. The design of the study provides one of the main independent variables: Twitter section versus regular section based. The creation of the second independent variable, enjoyment or non-enjoyment of Twitter as a subgroup of the Twitter sections is described below.

\subsubsection{Engagement}

Our scale of engagement was adapted from Krause and Coates' (2008) assessment of first-year student engagement to be applied to our study of Twitter as a course tool (discussed above). We included a list of 24 items where participants were asked to indicate their level of agreement on a five point scale from strongly disagree to strongly agree where one was strongly disagree and five was strongly agree. Table 2 includes measures of construct validity and reliability for four engagement scales including: academic, peer, intellectual, and beyond-class. The table includes values calculated for each construct loading $(\lambda)$, overall variance explained $(\sigma)$, and Cronbach's alpha as a measure of reliability $(\alpha)$.

Three of the four scales loaded satisfactorily (peer, intellectual, and beyond-class). This resulted in three additive variables - one for each dimension. Academic engagement, however, had low reliability at only 0.45 . Removing items from the factor analysis (e.g. the third and fifth items listed in Table 1) did not result in an adequate alpha (0.56). We chose to leave this construct in the analysis to examine how tweeting may affect academic engagement which is a primary goal of higher education. Thus, we created an additive variable for academic engagement. Finally, even with these issues with academic engagement, it did load successfully with the other dimensions into an overall engagement scale (all 24 items loaded with an alpha of 0.82).

As previously stated, we did not include their measures of "transition engagement" or "student-staff engagement." Both of these dimensions address student perceptions of larger university organization and were not appropriate for the present study. We also did not include their measures of "online engagement" as both courses were delivered in a face-to-face mode. While Twitter created an online component, the scale from Krause and Coates measures interactions that occur solely in a computermediated environment. 
Table 1

Construct validity and reliability for engagement scales

\begin{tabular}{|l|l|l|l|}
\hline \multicolumn{1}{|c|}{$\sigma^{2} \%$} & $\alpha$ \\
\hline Academic Engagement $(\mathrm{N}=5)$ & 0.72 & 33.51 & 0.45 \\
I regularly study on the weekends & & \\
I regularly seek advice and help from my professor or teaching & & & \\
assistant & 0.65 & & \\
I rarely skip classes & 0.15 & & \\
I regularly ask questions in class & 0.38 & & \\
I usually come to class having completed readings or assignments & & & \\
\hline Peer Engagement $(\mathrm{N}=8)$ & & 93.7 & 0.82 \\
I regularly work on other students on course areas with which I & & & \\
have problems & 0.79 & & \\
I regularly get together with other students to discuss classwork & 0.79 & & \\
I regularly study with other students & 0.82 & & \\
Studying with other students is useful to me & 0.77 & & \\
I regularly work with other students on projects during class & & \\
I regularly borrow course notes and materials from friends in the & 0.58 & & \\
same class & & & \\
I feel part of a group of students and faculty committed to learning & 0.40 & & \\
There is a positive attitude towards learning among my fellow & 0.48 & & \\
students & & & \\
\hline Intellectual Engagement (N = 5) & & \\
I enjoy the intellectual challenge of subjects covered in the course & 0.85 & & \\
I get a lot of satisfaction from studying & & \\
The lectures often stimulate my interests in the subjects & 0.74 & & \\
I am finding my course intellectually stimulating & & \\
I am usually motivated to study & & \\
\hline
\end{tabular}

\subsubsection{Twitter enjoyment}

Students in the experimental class were also asked to answer open-ended questions to give feedback on their experience using Twitter for the class. Four open-ended questions were included on the questionnaire given to the students enrolled in the experimental conditions. These questions included:

- "Describe your experience with Twitter over the past semester. What did you like? What did you not like?"

- "Compare this course to your other general education courses that did not use Twitter. Did you find yourself enjoy this class more or less? Did it affect your involvement during lecture or outside of the classroom?"

- "Besides the fact that you got points for using Twitter to answer questions, do you think it affected your grades and/or classroom performance any other way? If so, how?"

- "Did you ever use Twitter to ask a question or make a comment during lecture? Do you think the ability to do this added to your classroom experience?" 
We examined answers to these questions to assess students' attitudes towards Twitter. Those that expressly stated liking or enjoying Twitter $(\mathrm{N}=37)$ were coded as "1." These are students who made comments such as "I did like the whole idea of posting our ideas on Twitter instead of writing the answers on paper and handing them to you." Those who expressed not enjoying Twitter $(\mathrm{N}=25)$ received a " 2 ." These are students who made comments such as "I honestly hate Twitter. It is just another site where people blab about their life." Those who reported mixed feelings (liking some components and not liking others; $\mathrm{N}=128$ ) were coded as " 3 ." Those that did not answer the open-ended questions were not included $(\mathrm{N}=15)$.

\subsection{Procedure}

The study took place at a mid-sized state level comprehensive university. There were at total of four sections of two introductory level general education courses. These courses were large (enrollment up to 90 students in each section), face-to-face, and lecture-based (Introduction to Cultural Anthropology and Introduction to Sociology). Prior to the beginning of the Fall 2011 semester, the researchers randomly assigned (through two coin flips) which course would be the control group (have no Twitter assignments) and which course would be the experimental group (have Twitter) (see Table 2) for the entire fifteen-week semester. On the first day of the class, students were notified verbally, and on the syllabus, if they were enrolled in a "Twitter" class. In the control conditions, students were not notified of the other sections using Twitter.

Table 2

Schedules and random assignment for conditions

\begin{tabular}{|l|l|l|l|}
\hline Course & Days Offered & Time Offered & Assignment \\
\hline Cultural Anthropology & Tuesdays \& Thursdays & $8-9: 15$ & Control \\
\hline Cultural Anthropology & Tuesdays \& Thursdays & $11-12: 15$ & Experimental \\
\hline Sociology & Monday, Wednesday, Friday & $10-10: 50$ & Control \\
\hline
\end{tabular}

Prior to the beginning of the semester, the two researchers developed policies on how Twitter would be utilized in the courses. ${ }^{1}$ The two courses in each discipline would be taught exactly the same way (e.g. same text, number of assignments, lectures, nonTwitter assessments) with the difference being restricted to the use of Twitter in the experimental conditions. In both the experimental and control sections across disciplines, students were given seven low-stakes writing assignments with each instructor dropping the students' two lowest scores when calculating final grades. In the control conditions, students did these writings on the prompt in class. In the experimental conditions, students were asked to post their response to a dedicated course Twitter backchannel dedicated to each assignment. Students in the experimental condition could also use Twitter to live tweet during course films, ask questions during lecture, and send questions about course materials or procedures to their instructor. Instructors also posted websites, stories, and comments relevant to course material to a class Twitter feed.

After completion of all seven assignments, students in all four of the classes were asked to complete a pen/paper questionnaire on their perceptions of their classroom experience. As discussed above, they answered questions relating to their perception of their engagement. Further, students in the experimental conditions answered questions

${ }^{1}$ These policies will be made available upon request. 
related to their Twitter experience. They were also asked to tweet further suggestions and comments to the course Twitter feed. This data is utilized in the conclusion to help explain our quantitative findings.

\section{Results}

There were three different steps of analyses to test the hypotheses sets using SPSS 19. First, we tested whether the two courses could be collapsed together in subsequent tests. Second, we analyzed (either with the two courses collapsed together or separated out as a result of the first test) if there were significant differences between the experimental conditions and control conditions for each dependent variable. Finally, we analyzed for significant differences on the dependent variables for those who enjoyed Twitter and those who did not (Table 4). The findings are reported by dependent variable below. Missing data was handled through cross-wise deletion. As such, the results tables include sample size for each hypothesis test.

\subsection{Engagement in Twitter vs. control conditions}

The results for all of the engagement hypotheses are shown in Table 3. Before testing the engagement hypotheses, we explored whether overall engagement was statistically different between the two courses and found that the difference was not significant $(t=$ $0.68, d f=188, p=0.50$ ). Therefore, we collapsed the two classes together for the test of hypothesis 2a, i.e. overall engagement depending on if students had been in a Twitter course or in a control course. The test revealed that while the difference approached significance one-tailed, the difference actually favored higher overall engagement in the classes without Twitter ( $t=-1.64, d f=188, p=0.103$ two-tailed). Further, in order to provide an overall benchmark for experimental tests we included a calculation of Cohen's $\mathrm{d}$ whereby values around 0.20 are small, 0.50 are medium, and 0.80 are large (Cohen, 1988). The effect size for the Twitter manipulation was small (0.24). This results in a rejection of hypothesis $2 \mathrm{a}$.

There was no significant difference in academic achievement between Anthropology and Sociology $(\mathrm{t}=0.13, \mathrm{df}=195)$ resulting in collapsing the two together for analysis. There was a significant difference in academic engagement between the two conditions $(\mathrm{t}=-3.46, \mathrm{df}=195 *)$. However, the control condition was significantly more academically engaged then the Twitter class. This is counter to our expectations. Further, this effect size is medium (Cohen's $d=0.50$ ). Overall, this suggests we reject hypothesis $2 b$.

Levene's test for equality of variance indicates that there is a difference in variance between the two courses for both "peer engagement" and "intellectual engagement." For each, a Mann-Whitney U indicated that we can assume that the distribution of peer engagement is the same across courses $(p=.135$ and $p=0.06$ respectively). In the collapsed test between Twitter sections and regular sections, we find that there is no significant difference between the two in peer engagement $(t=-1.47, d f=$ $200, p=0.144)$ and intellectual engagement $(t=-0.001, \mathrm{df}=203, p=.99)$. While both hypotheses $2 \mathrm{c}$ and $2 \mathrm{~d}$ are rejected, it is interesting to note the differences in effect size. Peer engagement (0.21) and intellectual engagement (0.01) both have small effect sizes, however intellectual engagement almost does not register.

Similarly, there was no significant difference between the two courses in terms of beyond-classroom engagement $(t=1.17, d f=202, p=0.242)$. Further, there was no 
significant difference in beyond-class engagement for the Twitter and regular sections $(t$ $=0.56, d f=202, p=0.578)$. With a very small effect size $(0.04)$ hypothesis $2 \mathrm{e}$ is also rejected.

Table 3

Descriptive statistics and independent sample test (IST) for engagement measures

\begin{tabular}{|c|c|c|c|c|}
\hline & Anthropology & Sociology & Twitter & Control \\
\hline \multicolumn{5}{|c|}{ Overall Engagement } \\
\hline Mean (S.D.) & $79.88(11.06)$ & $81.01(11.71)$ & $\begin{array}{l}79.03(12.54) \\
\mathrm{N}=93\end{array}$ & $\begin{array}{l}81.72(9.97) \\
\mathrm{N}=97\end{array}$ \\
\hline IST & \multicolumn{2}{|c|}{$\mathrm{t}=0.68, \mathrm{df}=188$, n.s. } & \multicolumn{2}{|c|}{$\begin{array}{l}\mathrm{t}=-1.64, \mathrm{df}=188, \mathrm{n} . \mathrm{s} \\
\text { Cohen's d }=0.24^{\mathrm{a}}\end{array}$} \\
\hline \multicolumn{5}{|c|}{ Academic Engagement } \\
\hline Mean (S.D.) & $15.48(3.26)$ & $15.54(2.89)$ & $\begin{array}{l}14.75(3.15) \\
\mathrm{N}=96\end{array}$ & $\begin{array}{l}16.23(2.85) \\
\mathrm{N}=101\end{array}$ \\
\hline IST & \multicolumn{2}{|c|}{$\mathrm{t}=0.13, \mathrm{df}=195, \mathrm{n} . \mathrm{s}}$. & \multicolumn{2}{|c|}{$\begin{array}{l}\mathrm{t}=-3.46^{*}, \mathrm{df}=195 \\
\text { Cohen's d }=0.50^{\mathrm{b}}\end{array}$} \\
\hline \multicolumn{5}{|c|}{ Peer Engagement } \\
\hline Mean (S.D.) & $23.87(6.13)$ & $25.11(5.16)$ & $\begin{array}{l}23.88(5.75) \\
N=97\end{array}$ & $\begin{array}{l}25.05(5.59) \\
\mathrm{N}=105\end{array}$ \\
\hline IST & \multicolumn{2}{|c|}{ MW-U, $\mathrm{p}=0.14$, n.s. } & \multicolumn{2}{|c|}{$\begin{array}{l}\mathrm{t}=-1.47, \mathrm{df}=200, \mathrm{n} . \mathrm{s} \\
\text { Cohen's d }=0.21^{\mathrm{a}}\end{array}$} \\
\hline \multicolumn{5}{|c|}{ Intellectual Engagement } \\
\hline Mean (S.D.) & $18.03(3.43)$ & $17.11(3.98)$ & $\begin{array}{l}17.57(3.82) \\
\mathrm{N}=99\end{array}$ & $\begin{array}{l}17.56(3.68) \\
N=106\end{array}$ \\
\hline IST & \multicolumn{2}{|c|}{ MW-U, p = .06, n.s. } & \multicolumn{2}{|c|}{$\begin{array}{l}\mathrm{t}=-0.001, \mathrm{df}=203, \mathrm{n} . \mathrm{s} \\
\text { Cohen's } \mathrm{d}=0.00^{\mathrm{a}}\end{array}$} \\
\hline \multicolumn{5}{|c|}{ Beyond-Class Engagement } \\
\hline Mean (S.D.) & $22.50(4.33)$ & $23.20(4.14)$ & $\begin{array}{l}23.02(4.55) \\
\mathrm{N}=98\end{array}$ & $\begin{array}{l}22.69(3.95) \\
\mathrm{N}=106\end{array}$ \\
\hline IST & \multicolumn{2}{|c|}{$\mathrm{t}=1.17, \mathrm{df}=202$, n.s. } & \multicolumn{2}{|c|}{$\begin{array}{l}\mathrm{t}=0.56, \mathrm{df}=202, \mathrm{n} . \mathrm{s} \\
\text { Cohen's } \mathrm{d}=0.04^{\mathrm{a}}\end{array}$} \\
\hline
\end{tabular}

MW-U indicates the use Mann-Whitney U, a non-parametric independent samples test. In all other instances, the independent samples t-test is reported.

$* \mathrm{p}<0.01$, n.s. stands for not significant; ${ }^{\mathrm{a}}$ refers to small effect sizes, ${ }^{\mathrm{b}}$ refers to medium effect sizes

\subsection{Engagement in enjoyed vs. did not enjoy}

We also examined if those who enjoyed Twitter were significantly different in engagement than those who did not enjoy Twitter within the experimental condition (all results reported in Table 4). Students who enjoyed Twitter reported higher perceptions of overall engagement than those who did not enjoy using Twitter $(t=2.90, d f=60, p<$ $0.01)$. The effect size is approaching large (0.75) which overall supports hypothesis 3a. Students in the Twitter classes who enjoyed Twitter were significantly more likely to perceive themselves as academically engaged than those who did not enjoy Twitter $(\mathrm{t}=$ 2.14, df =61). The effect size was medium (0.55) providing further support for hypothesis $3 b$. 
Table 4

Descriptive statistics and independent sample test (IST) for enjoy vs. not enjoy subgroups

\begin{tabular}{|l|l|l|l|}
\hline & $\begin{array}{l}\text { Descriptive } \\
\text { Statistics }\end{array}$ & $\begin{array}{l}\text { Independent } \\
\text { Samples Test }\end{array}$ \\
\hline & Enjoy & Not Enjoy & \\
\hline Engagement & & & \\
\hline Overall Combined & $\begin{array}{l}82.70(11.01) \\
\mathrm{N}=37\end{array}$ & $\begin{array}{l}73.48(13.93) \\
\mathrm{N}=25\end{array}$ & $\begin{array}{l}\mathrm{t}=2.90^{* * *} \\
\mathrm{df}=60 \\
\text { Cohen's d }=0.75^{\mathrm{b}}\end{array}$ \\
\hline Academic Combined & $15.59(3.02)$ & $\begin{array}{l}13.92(3.08) \\
\mathrm{N}=26\end{array}$ & $\begin{array}{l}\mathrm{t}=2.14^{*} \\
\mathrm{df}=61 \\
\text { Cohen's d }=0.55^{\mathrm{b}}\end{array}$ \\
\hline Peer Combined & $25.23(5.86)$ & $\begin{array}{l}22.69(5.48) \\
\mathrm{N}=26\end{array}$ & $\begin{array}{l}\mathrm{t}=1.75^{\mathrm{t}} \\
\mathrm{d}=64 \\
\text { Cohen's d }=0.44^{\mathrm{a}}\end{array}$ \\
\hline Intellectual Combined & $18.13(3.35)$ & $\begin{array}{l}15.42(4.66) \\
\mathrm{N}=26\end{array}$ & $\begin{array}{l}\mathrm{t}=2.74^{* *} \\
\mathrm{df}=64 \\
\text { Cohen's d }=0.69^{\mathrm{b}}\end{array}$ \\
\hline $\begin{array}{l}\text { Beyond-Class } \\
\text { Combined }\end{array}$ & $23.98(3.66)$ & $\begin{array}{l}21.32(4.68) \\
\mathrm{N}=25\end{array}$ & $\begin{array}{l}\mathrm{t}=2.55^{*} \\
\mathrm{df}=63 \\
\text { Cohen's d }=0.64^{\mathrm{b}}\end{array}$ \\
\hline
\end{tabular}

${ }_{p}<0.05$, one-tailed, $* p<0.05$, two-tailed, $* * *<0.01$, two-tailed, n.s. stands for not significant; ${ }^{a}$ refers to small effect sizes, ${ }^{\mathrm{b}}$ refers to medium effect sizes

Those who enjoyed Twitter were more likely to report being engaged with peers $(\mathrm{t}=1.75, d f=64, p<0.05$ one-tailed $)$ and being intellectually engaged $(t=2.74, \mathrm{df}=64$, $p<0.01)$ than those who did not enjoy Twitter. The effect size for peer engagement approached medium (0.44) while the effect size for intellectual engagement at 0.69 , while medium, is stronger. Those who enjoyed Twitter were significantly more likely to report engagement beyond the classroom than those who did not $(t=2.55, d f=63, p<0.05)$. Further, there was a medium effect size (0.64). Thus, hypotheses $3 \mathrm{c}, 3 \mathrm{~d}$, and $3 \mathrm{e}$ were all supported.

\section{Discussion}

We found no significant affect of Twitter on student engagement when comparing the control condition (no Twitter) to the experimental condition (Twitter was used). However, in the experimental condition, there was a significant affect of Twitter enjoyment on student engagement with those saying they enjoyed Twitter being significantly more engaged than those who did not enjoy Twitter. This was the case across four large lecture courses across two disciplines (Anthropology and Sociology). Following the work of Krause and Coates (2008), engagement consisted of four dimensions: academic, intellectual, peer, and beyond-class. Below we discuss our problematic findings in terms of engagement in general and academic engagement in particular. We then discuss our enjoyment findings and provide student comments that help contextualize these results. After this we discuss some study limitations and provide suggestions for future use of Twitter in the classroom. 


\subsection{Lack of significant findings in engagement}

We failed to support our hypotheses that students in the Twitter sections would perceive themselves as more engaged than those in the control sections. This was the case for overall engagement (the composite measure), intellectual, peer, and beyond-classroom engagement. In examining effect sizes (see Table 3), note that there is almost no effect size on intellectual and beyond-class engagement further indicating that there was no perceivable difference between students in the experimental and control conditions. There were weak effects for overall and peer engagement (at 0.24 and 0.21 respectively). Specifically, the average person in the experimental group would score higher than approximately $58 \%$ of the control group in terms of their perception of their overall and peer engagement (Cohen, 1988). While this difference was not significant, there is some indication that the Twitter manipulation did have an effect on these types of engagement.

Due to lack of significant difference and the small or non-existing effect sizes, we turn to the qualitative data for possible explanations. Previous research on the effect of social media on student engagement has noted that the type of media and students preferences do mediate affects on academic performance (e.g., Saeed, Yang, \& Sinnappan, 2009). Previous research on Twitter in the classroom has already contributed to this discussion (Kassens-Noor, 2012). For example, Wakefield, Warren, and Alsobrook (2011) note some complicating factors of incorporating technology into the classroom. These include: students not recognizing choice of technology use as a first step in generating social connections, students opting out of connections, students feeling uncomfortable with technology, and students choosing to not participate to challenge social "norms" of growing technology reliance. Our research adds to this list of issues primarily in relation to familiarity and willingness to try new approaches to learning.

First, we found that many students had difficulty with the technology due to lack of familiarity. As one student commented, "I tried [to use Twitter to ask a question or make a comment] but my phone did not cooperate. I also found it hard to learn how to use Twitter." Both authors frequently met with students to discuss why their tweets were not posting to the class feed. Repeatedly, students had difficulty knowing how to set up an account (even with a classroom session on how to do so) or how to tweet to a backchannel (e.g. forgetting to leave a space between the tweet and the backchannel address).

Second, students were reluctant to adapt to unfamiliar technology and classroom expectations. Many students did not enjoy using Twitter simply because they had not used it before. As one student commented, "I didn't like it because I don't use Twitter, so I had to learn how to use it and it was difficult to remember to answer questions on it because it was unfamiliar." One of the most frequent comments indicated that Twitter was not their preferred social media outlet. More than one student asked why Facebook was not used instead. "Twitter made my grade go down. I just could not get into it the way I do Facebook. I was never on Twitter until this class."

Similar to findings in Wakefield, Warren, and Alsobrook (2011), with lack of previous use, students in our study were now required to create and monitor a new account. In keeping with what has become normative at universities throughout the country, students not only had the sites they had chosen to interact with (e.g., Facebook), but were also encouraged to maintain a digital relationship with a university email system, an online course management system (e.g., Blackboard), as well as textbook and study aid websites. From our students' perspectives, the addition of a Twitter account (with the need to remember additional user names and passwords) created what we came to 
understand as "log-in overload." Students would comment on not liking Twitter because they would "forget" to check the feed, to do the assignment, or even the password to log into their accounts. Because it was outside their normal everyday technology use, they felt it created an undue burden. Even though this is the case, it must be noted that some students opened up to the possibilities presented by this new technology and added it to their repertoire. One student summarized this succinctly: "When you start not having one [a Twitter account] it was dreadful setting it up just for the purpose of class and trying to figure out how it worked. Now, I use it all the time and not only for class."

Not only did students not want to change their technology routine, there were also those who were leery about changing their classroom routine. For example, they were resistant to bringing devices to class. "No, I didn't [use Twitter to ask a question or make a comment]. I do not bring a laptop or smart phone to class." In another way, while students may have appreciated access to other students' opinions, they did not want to change their routine in the same way. "I liked being able to see classmates' answers. I didn't like having to get on the web and post my answers through Twitter. What happened to a pen and a pad?"

\subsection{Academic engagement}

Not only was academic engagement not significantly higher in Twitter sections than nonTwitter sections, the opposite was the case. Students in the control sections perceived themselves as more academically engaged than those who used Twitter. Indeed, unlike the other effect sizes discussed above, being in a control section had a moderate effect (at 0.50 ) on academic engagement. This indicates that the average person in the control group would score higher than $69 \%$ of the experimental group in terms of their perception of their academic engagement (Cohen, 1988).

There are several reasons that this may be the case. Recall that the measure created for academic engagement was problematic to begin with. The items in this measure did not successfully load. Examining items in this analysis may suggest reasons why. Items may also be problematic due to the culture of a large classroom (e.g. asking questions during class) and the home institution (e.g. asking questions of a teaching assistant and skipping classes). Thus, future research would need to revisit these measures in order to find items that are reliable.

Another limitation of this particular analysis is that due to confidential reasons we have no measures of student level (i.e. first year, second year), we cannot control for transfer students, or if students were retaking the course (having failed in a previous semester). Without this information it is unclear if there, for some unknown reason, was a concentration of more highly academically engaged students in particular sections. While assignment of conditions was randomized through a coin flip, it was not possible to randomize student enrollment. Thus, it is possible that these results are due to student selection into particular sections. Both control sections were the earlier morning courses and it may be that less academically engaged students avoided enrolling in the early morning courses and/or academically motivated students may have selected into those early slots. These are issues that future research will need to address.

Twitter itself may have created this difference. It is possible that this social media served as a distraction rather than as a way to encourage students to participate. In particular, our measures of academic achievement asked about students skipping classes. Due to experimental design, students in the Twitter section could get low-stakes points without coming to class. They simply needed to watch the Twitter feed to know when a 
tweet was due. In the control conditions, all writings were due in-class with no previous warning. Therefore, it would have been easier for students in the Twitter section to skip without penalty. This is one potential that future research would need to address.

\subsection{Enjoyment \& engagement}

We also found that students who enjoyed using Twitter perceived themselves as more engaged (overall, academic, peer, intellectual, and beyond-class engagement). When examining the comments on the open-ended questionnaire, the reason behind this finding is clearer. Below we discuss the findings for enjoyment for each type of engagement.

First, students who enjoyed Twitter were more academically engaged (keep in mind the limitations of this particular scale). The effect size here is moderate (0.55). This indicates that the average person who enjoyed Twitter would score higher than approximately $69 \%$ of those who did not enjoy Twitter in terms of their perception of their academic engagement (Cohen, 1988). Anecdotal evidence helps explain why this is the case. Both professors received questions via Twitter outside of the classroom (e.g. clarifications of assignments, review questions for the test). At times, students would tweet links to outside material to clarify questions they had about course discussions. Further, some students tweeted back and forth with the researchers and their classmates during course films to apply course content to on screen content.

Second, the effect size of Twitter enjoyment on peer engagement is moderate (0.44). This indicates that the average person who enjoyed Twitter would score higher than approximately $66 \%$ of those who did not enjoy Twitter in terms of their perception of their peer engagement (Cohen, 1988). The discussion of academic engagement informs peer engagement as well. Students would tweet links to outside material to continue classroom discussions with each other. However, due to the structure of Twitter, it was not clear if students responded to each other outside of the class feed. This is supported in the qualitative data with comments such as, "It [Twitter] helped me participate with others so I could see what they thought also." Students also commented that the desired more ability to engage with their peers through Twitter. One student wrote, "I think we could also use Twitter for gettin' to know others in the class! So, have a list of our classmates' Twitter name!" Additionally, students recognized the potential for using Twitter to encourage interactions with other students. For example, one student requested that the instructor, "Post assignments that require us to interact with other students via Twitter, not just you [the instructor]." While these are not opportunities provided during this study, comments seem to suggest that they would be positive additions to increase enjoyment, which was essential to student engagement.

Third, there is some indication why there would be increased intellectual engagement when students enjoyed Twitter. The effect size of Twitter enjoyment on intellectual engagement is moderate (0.69). This indicates that the average person who enjoyed Twitter would score higher than approximately $76 \%$ of those who did not enjoy Twitter in terms of their perception of their intellectual engagement (Cohen, 1988). Again, posting links or retweeting links the professor posted relating to course material indicate engagement on an intellectual level with the topic area. Again, during films, instructors tweeted comments and questions relating the course material to the film. Students would tweet back answers for peer and instructor feedback. We argue that students who enjoy Twitter and who are watching these feeds may use their own ability to answer these questions as a measure of their subject knowledge. This also gave students a real time avenue to apply course material on a wide variety of topics. 
Fourth, the effect size of Twitter enjoyment on beyond-class engagement was moderate (0.64). This indicates that the average person who enjoyed Twitter would score higher than approximately $73 \%$ of those who did not enjoy Twitter in terms of their perception of their academic engagement (Cohen, 1988). Students may have had higher beyond-class engagement because Twitter allowed them to link up to each other and the instructor in an environment (large lectures) that normally does not encourage that type of interaction. At the same, it is important to note for all of these types of engagement, we do not have evidence of directionality. It is highly possible that students in extracurricular activities, those who already mix with other students, and those who feel a strong connection to the university (some measures of beyond-class engagement) may have been more likely to participate on the class Twitter feed.

Finally, overall engagement was higher for students who enjoyed using Twitter. The effect size of Twitter enjoyment on overall engagement was also moderate (0.75). This indicates that the average person who enjoyed Twitter would score higher than approximately $76 \%$ of those who did not enjoy Twitter in terms of their perception of their overall engagement (Cohen, 1988). Obviously the above effects combine in this variable (as this is a composite measure). Beyond this, some students noted increased engagement due to interactions through Twitter. For example, one student noted: "I was more involved in this course outside the classroom because of Twitter and online reviews." Students who did not enjoy Twitter provided further evidence for why this relationship between enjoyment and engagement may have existed. These students were reluctant to use it to engage with the course, the professor, or other students. Many students commented that they only did the minimum required and nothing more. "I wasn't a fan at first, but learned it enough to complete my assignments. Didn't really read what others posted, just did what I was required." Others enjoyed seeing other peoples' comments, but did not want to comment themselves - thus they were not willing to fully engage. Further, some students indicated they would be willing to engage more if others did the same. In particular, due to the teaching responsibility of the instructors, they were not able to respond to tweets in real time. "I don't think twitter was used much during class time for questions or comments because no one would tweet back during that time."

\subsection{Limitations}

We have already mentioned several limitations to this study. First, due to anonymity required, we did not have demographic or final percent grades tied to student's responses on the questionnaire. This created problems with explaining research findings and also did not allow us to examine the effect of engagement and/or Twitter on academic performance.

Second, a limitation on this and most other analyses based in the academic environment is that researchers cannot utilize randomization techniques in assigning participants into control or experimental conditions. We would note, however, that these sections are all filled from the same student pool that needs to take introductory level general education courses in the social sciences. These courses are designed to meet the needs of any random student at this level. Yet, as we suggested above, there may be selection effects due to transfers, course retakes, and it is possible for upper division students to enroll in introductory courses after taking some higher level class in either field. Given, however, our large sample size, we do not think these factors overwhelmingly impact our results, but cannot be sure.

Third, along these lines, we did not include a pretest of student engagement. Coupled with our inability to randomize students into conditions, we therefore cannot 
report with much certitude that the results come from the manipulation rather that selection effects. We certainly would suggest, in the future, a pre-test be conducted in order to explore this possibility.

Finally, we are unable to clearly provide directionality in our analyses. As mentioned above, while we did find that students who enjoyed Twitter were more engaged beyond-class, it is unclear if Twitter caused this or if students who are generally more social are more likely to adopt new social media tools and use them more extensively. This is the case with all types of engagement and, again, suggests the need for a pre-test of engagement levels to see if there is a change throughout the semester. While this solution would not be perfect (i.e. other classes, campus experiences, or life activities may effect engagement), including these measures would provide stronger evidence of directionality.

\subsection{Moving forward with Twitter in the classroom}

Our findings and anecdotal experiences suggest several possible avenues to increase enjoyment and engagement using Twitter in the undergraduate lecture hall. Students could be encouraged to tweet during classes. Perhaps they could tweet to prompts during class. Using software programs that allow you to take polls via Twitter could make it possible to ask opinion or multiple-choice questions. At one point, the first researcher added a live Twitter feed to the bottom of PowerPoint presentations. To us, this did seem to be distracting, but provides potential if that live feed were linked to a special backchannel set up solely for that day's lecture. Finally, a student teaching assistant could be charged with monitoring the feed and bringing questions to your attention similarly as in Rankin (2009). This may be particularly useful for the students who commented that they liked to be able to state their opinions more anonymously in a large classroom environment (Rockinson-Szapkiw \& Szapkiw, 2011; Wakefield, Warren, \& Alsobrook, 2011).

But it is not just engagement with instructors that students desired - and lacked. Some students also commented on the lack of Twitter use by other students. One student tweeted that they wanted the instructors to "use Twitter to get students to talk to each other outside of class. To study and discuss things we talk about in class." Several students were discouraged that the ability to use smartphones and computers in class was taken advantage of by some in order to text, but not to engage in class discussion similarly (Galagan, 2010). This will necessarily be problematic in any university where students do not have universal access to technology in the classroom. What this suggests is that any attempt to increase technological use during lectures will necessarily create two experiences - one for students with access and one for those without. We found that this creates ethical considerations that each instructor will need to consider for him or herself.

Comments made by students in the open-ended portion of the survey indicated that, as suggested by Ramaley and Zia (2005), smartphone usage was not universal and many did not own mobile devices to utilize in the classroom (for real-time Twitter questions, for example). As one student commented, "I don't have a smartphone, so I can only use it [Twitter] on a computer. And I forget about it [the assignment] by the time I get done with classes and have a computer." Recent nation-wide statistics support this inequity indicating that researchers and teachers must question the assumption of students' universal technology usage. For example, a 2012 poll by the PEW Hispanic Center indicates that while $90 \%$ of Hispanic young adults (18-19) own a cell phone (the 
study did not distinguish between smartphones and cell phones), only 57\% of the respondents residing in suburban areas owned the technology. In comparison, $79 \%$ of urban residents and $76 \%$ of rural residents owned cell phones (Livingston, 2011). Smith (2012) reports geographic usage rages of smartphone usage as: urban (50\%), suburban (46\%), and rural (34\%). As with the PEW Hispanic Center report, however, the largest jump in ownership between 2011 and 2012 occurred in the rural areas $(+13 \%)$, with the smallest in suburban areas $(+8 \%)$. Thus, while the assumption may be that rural cell phone usage is less common than urban or suburban areas, this is inaccurate. In addition, Smith (2012) reports a 14-point difference of smartphone ownership among 18-29 year olds whose annual household income was less than $\$ 30,000$ and over $\$ 30,000$ (58\% vs. $72 \%$, respectively). As universities continue to recruit students from both diverse racial/ethnic and socio-economic backgrounds, we argue this will continue to be a factor in understanding why Generation Net students may be resistant to new technology or social media tools.

\subsection{Final thoughts}

While students may be hesitant to use Twitter due to lack of familiarity and unwillingness to adapt to new techniques, in the final analysis most students were receptive to the attempt. In fact, a large theme we found was that students appreciated the course and the instructor, even if they were not wild about Twitter. In the words of one student: "I am not fond of Twitter, but I do like how the teacher is trying to use new and current tech in the class to keep it up-to-date and interesting." Indeed, that is what our analysis shows. Students who enjoyed Twitter perceived themselves as significantly more engaged across the board than those who did not enjoy Twitter. However, there was no significant difference in engagement between Twitter courses and non-Twitter courses outside of academic engagement. What does this mean? Put simply: the use of the technology did not detract from the educational experience overall, and for those that liked it - it enhanced. As one student summarized, "I like this class, but I'll never use Twitter again."

What we have here is a cautionary tale. We began the process viewing Twitter as a tool to increase student engagement, and, while that may be the case for some, we have to give Generation Net its own time to explore its preferences, its desires, and what its members' ultimately views as useful. Universities are certainly the place to explore these tools, but we should not expect mass acceptance of new tools that many faculty members have been convinced students want. In retrospect, we each concluded that the most important step to increasing student engagement through providing multiple channels for communication is to allow students drive social media selection. Once a tool is adopted into the classroom, professors need to be cognizant of the social factors impacting social media use and students' reluctance to engage with the unfamiliar. As such, it is necessary to approach any social media tool as one would any other skill we expect our students to acquire and apply - teach how to do so effectively and efficiently. Given these approaches, it appears that social media can potentially increase student engagement.

\section{Acknowledgements}

A previous version of this research was presented at the 2012 Faculty Summer Institute at the University of Illinois at Urbana-Champaign and the Annual Western Illinois University Innovations in Teaching, Research and Creative Activities Symposium. The authors would like to thank Krista Bowers Sharpe for her contribution to this research. 


\section{References}

Azevedo, H. (2011, April 26). The Netherlands ranks \#1 worldwide in penetration for Twitter and Linkedin. Comscore [Press release]. Retrieved from http://bit.ly/hOpdAb.

Baird, D. E., \& Fisher, M. (2005). Neomillennial user experience design strategies: utilizing social networking media to support "always on" learning styles. Journal of Educational Technology Systems, 34(1), 5-32.

Barnes, K., Marateo, R. C., \& Ferris, S. P. (2007). Teaching and learning with the Net Generation. Innovate 3(4). Retrieved from http://www.innovateonline.info/.

Bennet, S., Maton, K., \& Kervin, L. (2008). The 'digital natives' debate: A critical review of the evidence. British Journal of Educational Technology, 39(5), 775-786.

Blankenship, M. (2011). How social media can and should impact higher education. Education Digest: Essential Readings Condensed for Quick Review, 76(7), 39-42.

Carini, R. M., Kuh, G. D., \& Klein, S. P. (2006). Student engagement and student learning: testing the linkages. Research in Higher Education, 47(1), 1-32.

Cohen, J. (1988). Statistical power analysis for the behavioral sciences (2nd ed.). Hillsdale, NJ: Lawrence Earlbaum Associates.

Combes, B. (2006). Techno savvy and all-knowing or techno-oriented? Information seeking behaviour and the Net Generation. IASL Reports 2006: The Multiple Faces of Literacy, Reading, Knowing, Doing, Lisbon, Portugal.

Combes, B. (2007). Techno savvy or just techno oriented? How do the 'Net Generation' search for information? Paper presented at the ASLAXX Biennial Conference, Adelaide, Australia.

Combes, B. (2008). The net generation: tech-savvy or lost in virtual space? Paper presented at the 37th Annual Conference of the IASL, Berkeley University, California.

Cottle, S. (2011). Media and the Arab uprisings of 2011: Research notes. Journalism, 12(5), 647-659.

Dunlap, J. C., \& Lowenthal, P. R. (2009). Tweeting the night away: Using Twitter to enhance social presence. Journal of Information Systems Education, 20(2), 129-135.

Ewell, P. T. (2008). US accreditation and the future of quality assurance: A tenth anniversary report from the Council on Higher Education Accreditation. Washington, DC: CHEA Institute for Research and Study of Accreditation and Quality Assurance.

Exploring the use of Twitter around the world. (2010, January). Sysmos, Inc. [Web log post] Retrieved from http://www.sysomos.com/insidetwitter/geography/.

Fox, B. I., \& Varadarajan, R. (2011). Use of twitter to encourage interaction in a multicampus pharmacy management course. American Journal of Pharmaceutical Education, 75(5), 1-8.

Galagan, P. (2010). Burp, chatter, tweet: New sounds in the classroom. $T+D, 64(7), 26-$ 29.

Gonyea, R. M., \& Kuh, G. D. (2009). NSSE, organizational intelligence, and the institutional researcher. New Directions for Institutional Research, 2009(141), 107113.

Hannafin, M. J., \& Land, S. M. (1997). The foundations and assumptions of technologyenhanced student-centered learning environments. Instructional Science, 25, 167-202.

Hannay, M., \& Fretwell, C. (2011) The higher education workplace: meeting the needs of multiple generations. Research in Higher Education Journal, 10(March), 1-12. Retrieved from http://www.aabri.com/rhej.html.

Hastie, M., Chen, N.-S, \& Smith, R. (2011). Negotiating content with learners using technology enhanced teaching and learning solutions. Knowledge Management \& ELearning: An International Journal, 3(3), 412-427.

Hargittai, E., \& Litt, E. (2012). Becoming a tweep. Information, Communication \& Society, 15(5), 680-702. doi: 10.1080/1369118X.2012.666256 
Junco, R., Heibergert, G., \& Loken, E. (2011). The effect of Twitter college student engagement and grades. Journal of Computer Assisted Learning, 27(2), 119-132. doi: $10.1111 / \mathrm{j} .1365-2729.2010 .00387 . \mathrm{x}$

Kassens-Noor, E. (2012). Twitter as a teaching practice to enhance active and informal learning in higher education: The case of sustainable tweets. Active Learning in Higher Education, 13(1), 9-21. doi:10.1177/1469787411429190

Krause, K.-L., \& Coates, H. (2008). Students' engagement in first-year university. Assessment \& Evaluation in Higher Education, 33(5), 493-505. doi:10.1080/02602930701698892

Kuh, G. D., Cruce, T. M., Shoup, R., Kinzie, J., \& Gonyea, R. M. (2008). Unmasking the effects of student engagement on first-year college grades and persistence. The Journal of Higher Education, 79(5), 540-563.

Kuh, G. D. (2009). What student affairs professionals need to know about student engagement. Journal of College Student Development, 50(6), 683-706.

Laird, T. F. N., \& Kuh, G. D. (2005). Student experiences with information technology and their relationship to other aspects of student engagement. Research in Higher Education, 46(2), 211-233. doi: 10.1007/s 11162-004-1600-y

Livingston, G. (2011). Latinos and digital technology, 2010. Research Report February 9, 2011. Retrieved from Pew Research Center: http://pewhispanic.org/files/reports/134.pdf.

Lowe, B., \& Laffey, D. (2011). Is twitter for the birds?: Using twitter to enhance student learning in a marketing course. Journal of Marketing Education, 33(2), 183-192. doi: $10.1177 / 0273475311410851$

Luo, T. \& Gao, F. (2012). Enhancing classroom learning experience by providing structures to microblogging-based activities. Journal of Information Technology Education: Innovations in Practice, 11, 199-211. Retrieved from http://informingscience.org/jite/documents/Vol11/JITEv11IIPp199-211Luo1127.pdf.

Moran, M., Seaman, J., \& Tinti-Kane, H. (2011). Teaching, learning, and sharing: How today's higher education faculty use social media. Boston, MA: Pearson. Retrieved from http://www.babson.edu/Academics/Documents/babson-survey-researchgroup/teaching-learning-and-sharing.pdf.

National Research Council. (2003). Engaging schools: Fostering high school students' motivation to learn. Washington, DC: The National Academies Press.

Nicholas, D., Rowlands, I., \& Huntington, P. (2008). The information behaviour of the researcher of the future: A CIBER briefing paper. Retrieved from http://www.jisc.ac.uk/whatwedo/programmes/resourcediscovery/googlegen.aspx.

Oblinger, D. G., \& Hagner, P. (2005). Educating the Net Generation. Presented at Educause, Tempe, AZ, August. [PowerPoint]. Retrieved from http://www.educause.edu/section_params/conf/esem052/OneDayv2-HO.ppt\#3.

Oblinger, D., \& Oblinger, J. (2005). Is it age or IT: First steps toward understanding the Net Generation. Educause. Retrieved from http://www.educause.edu/research-andpublications/books/educating-net-generation/it-age-or-it-first-steps-towardunderstanding-net-generation.

Pascarella, E. T., Pierson, C. T., Wolniak, G. C., \& Terenzini, P. T. (2004). Firstgeneration college students: Additional evidence on college experiences and outcomes. The Journal of Higher Education, 75(3), 249-284.

Pascarella, E. T., \& Terenzini, P. T. (2005). How college affects students. San Francisco: Jossey-Bass.

Prensky, M. (2001a). Digital natives, digital immigrants. On the Horizon, 9(5), 1-6.

Prensky, M. (2001b). Digital natives, digital immigrants, part II: Do they really think differently? On the Horizon, 9(6): 1-6. doi: 10.1108/10748120110424843

Purcell, K. (2011, June 27). e-Reader ownership doubles in six months. Retrieved from 
Pew Internet \& American Life Project website: http://pewinternet.org/Reports/2011/E-readers-and-tablets/Report.aspx.

Ramaley, J., \& Zia, L. (2005). The real versus the possible: Closing the gaps in engagement and learning. Educause. Retrieved from http://www.educause.edu/research-and-publications/books/educating-netgeneration/real-versus-possible-closing-gaps-engagement-and-learning.

Rankin. M. (2009). Some general comments on the Twitter experiment. Retrieved from http://bit.ly/IOLjs.

Revere, L., \& Kovach, J. (2011). Online technologies for engaged learning: A meaningful synthesis for educators. Quarterly Review of Distance Education, 12(2), 113-124

Rockinson-Szapkiw, A. J., \& Szapkiw, M. (2011). Engaging higher education students through tweeting. Proceedings of Global Learn Asia Pacific 2011 (pp. 360-364), Melbourne, Australia, March.

Rutherford, C. (2010). Using online social media to support preservice student engagement. Journal of Online Learning and Teaching, 6(4).

Saeed, N., Yang, Y., \& Sinnappan, S. (2009). Emerging web technologies in higher education: A case of incorporating blogs, podcasts and social bookmarks in a web programming course based on students' learning styles and technology preferences. Educational Technology \& Society, 12(4), 98-109.

Silus, K., Millumäki, T., Huhtamäki, J., Tebest, T., Meriläinen, M., \& Pohjolainen, P. (2010). Students' motivations for social media enhanced studying and learning. Knowledge Management \& E-Learning: An International Journal, 2(1), 51-67.

Singer, D. (2010, August 15). Twitter's growth doubles, becomes more international. [Web log post]. $\quad$ Retrieved rom http://socialmediatoday.com/dirktherabbit/162555/twitter\%E2\%80\%99s-growthdoubles-becomes-more-international.

Smith, A. (2011, June 1). Twitter update 2011. Retrieved from http://pewresearch.org/pubs/2007/twitter-users-cell-phone-2011-demographics.

Smith, A. (2011b). Smartphone adoption and usage. (Research Report, July 11, 2011). Retrieved from http://pewinternet.org/Reports/2011/Smartphones.aspx.

Smith, A. (2012). 46\% of American adults are smartphone users. (Research Report, March 1, 2012). Retrieved from http://pewinternet.org/Reports/2012/SmartphoneUpdate-2012.aspx.

Tapscott, D. (1998). Growing up digital: The rise of the Net Generation. New York: McGraw-Hill.

Tyma, A. (2011). Connecting with what is out there!: Using twitter in the large lecture. Communication Teacher, 25(3), 175-181. doi: 10.1080/17404622.2011.579911

Wakefield, J. S., Warren, S. J., \& Alsobrook, M. (2011). Learning and teaching as communicative actions: A mixed-methods Twitter study. Knowledge Management \& E-Learning: An International Journal, 3(4), 563-584.

Young, J. R. (2009, November 22). Teaching with Twitter: Not for the faint of heart. The Chronicle of Higher Education. Retrieved from http://chronicle.com/article/TeachingWith-Twitter-Not-for/49230/. 